\title{
Numerical Simulation of a Cigarette during Smoking*
}

\author{
by \\ Bernhard Eitzinger ${ }^{l}$ and Stefan Pirker ${ }^{2}$ \\ ${ }^{1}$ WFT Research, 4050 Traun, Austria \\ ${ }^{2}$ Johannes Kepler University, 4020 Linz, Austria
}

\section{SUMMARY}

A mathematical model for a lit cigarette is derived, which predicts pressure, flow velocity, temperature and gas concentrations inside and outside the cigarette. It consists of a continuum-mechanical model for the flow and a discrete model for the chemical reactions occurring in the tobacco particles.

The cigarette model is simulated for a cigarette in a vertical position by methods known as computational fluid dynamics (CFD). Calculated temperature and gas concentration profiles are compared to measured data from the literature for smouldering, puffing and steady-draw. For thermophysical properties, such as temperature fields and burn rates, a good correspondence with experimental data was found. The correspondence with measured gas concentration profiles was also acceptable, even though the reaction model is rather simple. The results show the importance of including the surroundings of the cigarette in the computational domain.

Secondly, a cigarette in a horizontal position is simulated both for free smouldering and for smouldering on a substrate, as occurs, for example, during the ignition strength test. The results show certain qualitative differences between the two smouldering regimes in the flow pattern outside the cigarette and in the transfer of heat to the surroundings and to the substrate.

The proposed model offers two main advantages. Firstly, it does not need the input of any data, that can only be measured if the cigarette has been lit, such as temperature fields or burn rates. Secondly, with this model all types of smoking regimes such as smouldering, puffing and steadydraw can be simulated without making any modifications to the mathematical model or its parameters. Only the boundary conditions need to be adapted. [Beitr. Tabakforsch. Int. 21 (2005) 402-416]

\section{ZUSAMMENFASSUNG}

Es wird ein mathematisches Modell für eine glimmende Zigarette entwickelt, mit dessen Hilfe Druck, Strömungsgeschwindigkeiten, Temperaturen und Gaskonzentrationen innerhalb und außerhalb der Zigarette berechnet werden können. Das Modell besteht aus einem kontinuumsmechanischen Teil zur Beschreibung der Strömung und einem diskreten Teil, der die chemischen Reaktionen im Tabakstrang abbildet.

Die Modellgleichungen werden für eine Zigarette in vertikaler Lage mit Verfahren aus dem Bereich der numerischen Strömungsmechanik (CFD) gelöst. Ein Vergleich der berechneten Temperatur- und Gaskonzentrationsfelder mit in der Literatur dokumentierten Messdaten zeigt vor allem für die thermophysikalischen Eigenschaften wie Temperaturfelder und Abbrandraten eine gute Übereinstimmung. Trotz des einfaches Reaktionsmodells ist auch die Übereinstimmung mit gemessenen Gaskonzentrationsfeldern brauchbar. Die Ergebnisse zeigen aber auch, dass in solchen Simulationen die Umgebung der Zigarette in den Rechenbereich aufgenommen werden muss.

Weiters wird auch eine Zigarette in horizontaler Lage simuliert und zwar zum einen beim freien Glimmen und zum anderen beim Glimmen auf einer Unterlage, wie es zum Beispiel während eines standardisierten Tests zur Messung der Entflammneigung vorkommt. Es zeigen sich deutliche qualitative Unterschiede in den Strömungsfeldern außerhalb der Zigarette und im Wärmetransfer an die Umgebung bzw. an die Unterlage.

Das in dieser Arbeit vorgeschlagene Modell besitzt zwei wesentliche Vorteile. Zum einen benötigt es keine Daten als Parameter oder Eingangsgrößen, die erst nach dem Anzünden der Zigarette messtechnisch zur Verfügung stehen, wie zum Beispiel Temperaturfelder oder Abbrandraten. Zum anderen können mit diesem Modell alle denk- 
baren Abrauchvorgänge, insbesondere freies Glimmen, genormtes Abrauchen oder stationäres Anziehen an der Zigarette ohne Änderungen am Modell oder den Modellparametern simuliert werden. Es ist nur eine Anpassung der Randbedingungen erforderlich. [Beitr. Tabakforsch. Int. 21 (2005) 402-416]

\section{RESUME}

Un modèle mathématique d'une cigarette en combustion a été développé. Ce modèle permet de calculer la pression, la vitesse des flux, la température et les concentrations de gaz à l'intérieur et à l'extérieur de la cigarette. Le modèle consiste en une partie mécanique de continuum pour la description de la vitesse et une partie discrète schématisant les réactions chimiques dans le boudin de tabac.

Le modèle simule une cigarette en position verticale par un procédé du domaine de la mécanique des fluides numérique (CFD). La température calculée et les profils des concentrations de gaz sont comparés avec les données rapportées dans la littérature pour une combustion libre, une combustion au cours des bouffées et un tirage constant. Les propriétés thermophysiques comme la température et la vitesse de combustion sont en bon accord avec les données expérimentales. Malgré la simplicité du modèle, les profils des concentrations de gaz correspondent également bien aux données rapportées. Les résultats soulignent l'importance de prendre en considération l'environnement de la cigarette lors de telles simulations.

Ensuite, une cigarette en position horizontale est simulée, d'une part pour la combustion libre et d'autre part pour la combustion sur un substrat, comme c'est le cas par exemple au cours d'études sur la tendance à l'ignition des cigarettes. Certaines différences qualitatives peuvent être constatées entre les deux régimes de combustion dans les flux à l'extérieur de la cigarette et dans le transfert de chaleur vers l'atmosphère, ainsi que vers un substrat.

Le modèle proposé offre deux avantages principaux. D'une part, ce modèle ne nécessite pas des paramètres pouvant être mesurés seulement après l'ignition de la cigarette, comme la température ou la vitesse de combustion. D'autre part, ce modèle permet de simuler tous les types de régimes de fumage, comme la combustion libre, la combustion au cours des bouffées et le tirage constant sans pour autant modifier le modèle mathématique ou les paramètres du modèle. Il suffit seulement d'adapter les conditions limites. [Beitr. Tabakforsch. Int. 21 (2005) 402-416]

\section{INTRODUCTION}

The mathematical modelling of smouldering cigarettes started a long time ago $(1,2)$ and in the meantime quite sophisticated models for lit cigarettes have become available (3-9). The numerical treatment of these models, however, was limited by computational resources and the availability of appropriate numerical methods. For these reasons in the past models were either restricted to one spatial dimension $(2,4-6)$ or to specific flow regimes, such as smouldering $(3,5-7)$, puffing $(8,9)$ or steady-draw (4).
With computational fluid dynamics (CFD) it is possible to simulate flows, heat and mass transfer and chemical reactions. While CFD has for many years been successfully applied to advanced engineering tasks (10), it has only recently also been used for the simulation of cigarettes (7-9). The use of CFD has greatly enhanced the ability to solve complex systems of partial differential equations, but nevertheless some numerical difficulties remain. Consequently, several simplifications have been introduced such as using measured temperature fields and burn rates as input $(8,9)$, or neglecting the fluid flow as a transport mechanism during smouldering (7). As pointed out by Motohiko MurAmATSU (11), to date no mathematical model has been published which can be used to simulate both - smouldering and puffing - as occurs, for example, during machine smoking.

It is the goal of this study to develop such a model and to use it to simulate numerically a cigarette during smouldering and puffing.

Furthermore the model will only use a priori data of the cigarette's components and not make use of any a posteriori data, that is only available after the cigarette has been lit. The surroundings of the cigarette will be included in the flow domain, in order to avoid predetermining the numerical solution by imposing boundary conditions on the cigarette. The main goal will be to correctly describe the thermodynamics of lit cigarettes, and so only chemical reactions with significant energetic contributions will be included in the model. The results will be, for example, temperature, pressure, flow velocity and gas concentration fields. Global cigarette parameters such as the linear burn rate, ventilation and pressure drop will also be predicted. Finally, the results will be compared with measured data published in the literature, mainly the results by BAKER (12-15), but also measurements by MURAMATSU (16). Most of the model parameters are also taken from the literature (7-9,17-21).

\section{MATHEMATICAL MODEL}

The model is spatially three-dimensional and time-dependent. The computational domain includes the cigarette as well as the cigarette's environment. For most of the simulations, the cigarette will be placed in a vertical position. This allows us to assume rotational symmetry which reduces the model to two dimensions and greatly reduces the computational effort. A three-dimensional simulation of a lit cigarette in a horizontal position is possible without any modification of the mathematical model and was carried out for free smouldering and smouldering on a substrate.

\section{Basic concept}

The model combines two different approaches. On the one hand the description of the gas-flow is based on continuummechanics, while on the other hand the tobacco particles are treated by a discrete model. The two models interact by exchange of mass and energy, which can be conveniently described by source terms.

The gas-flow model covers flow velocity, pressure, density, gas temperature and gas composition and consists of the 
Table 1. Some important model parameters and initial values

\begin{tabular}{|c|c|c|c|c|c|c|}
\hline Parameter & Symbol & Unit & \multicolumn{4}{|c|}{ Initial value } \\
\hline Flow velocity vector & $\boldsymbol{v}$ & $\mathrm{m} / \mathrm{s}$ & \multicolumn{4}{|c|}{0} \\
\hline Density of gas mixture & $\rho$ & $\mathrm{kg} / \mathrm{m}^{3}$ & \multicolumn{4}{|l|}{133} \\
\hline Pressure of gas mixture & $p$ & $\mathrm{kPa}$ & \multicolumn{4}{|l|}{101.3} \\
\hline Gas temperature & $T$ & $\mathrm{~K}$ & \multicolumn{4}{|l|}{296} \\
\hline $\begin{array}{l}\text { Mass fraction of gas component } \\
\qquad i \in\left\{\mathrm{N}_{2}, \mathrm{O}_{2}, \mathrm{H}_{2} \mathrm{O}, \mathrm{CG}\right\}\end{array}$ & $Y_{i}$ & 1 & $\begin{array}{l}\mathrm{N}_{2} \\
0.77\end{array}$ & $\frac{\mathrm{O}_{2}}{0.23}$ & $\frac{\mathrm{H}_{2} \mathrm{C}}{0.0}$ & $\frac{\mid C G}{0.00}$ \\
\hline $\begin{array}{l}\text { Particle temperature } \\
\text { Initial particle mass }\end{array}$ & $\begin{array}{l}T_{\mathrm{p}} \\
m_{\mathrm{p} 0}\end{array}$ & $\begin{array}{l}\mathrm{K} \\
\mu \mathrm{g}\end{array}$ & \multicolumn{4}{|l|}{296} \\
\hline $\begin{array}{l}\text { Initial mass of particle components } \\
\qquad i \in\left\{\mathrm{H}_{2} \mathrm{O} \text {, tobacco, ash }\right\}\end{array}$ & $m_{\mathrm{p}, i, 0}^{\mathrm{p}, 0}$ & $\mu \mathrm{g}$ & $\frac{\mathrm{H}_{2} \mathrm{O}}{4.536}$ & $\frac{T}{2}$ & $\begin{array}{l}\text { Tobacco } \\
27.594\end{array}$ & Ash \\
\hline Time & $t$ & s & \multicolumn{4}{|l|}{0} \\
\hline Ambient air pressure & $p_{0}$ & $\mathrm{kPa}$ & \multicolumn{4}{|l|}{101.3} \\
\hline Particle surface area & $A_{\mathrm{p}}$ & $\mathrm{mm}^{2}$ & \multicolumn{4}{|l|}{0.368} \\
\hline Rate of evaporation per particle surface area & $J_{\text {Evap }}^{\mathrm{p}}$ & $\mathrm{kg} / \mathrm{m}^{2} \mathrm{~s}$ & \multicolumn{4}{|l|}{0.019} \\
\hline Emissivity of particle & $\epsilon_{\mathrm{p}}^{\text {Lvap }}$ & 1 & \multicolumn{4}{|l|}{0.9} \\
\hline Evaporation enthalpy of water & $h_{\text {Evap }}^{\mathrm{p}}$ & $\mathrm{MJ} / \mathrm{kg}$ & \multicolumn{4}{|l|}{2.26} \\
\hline Pyrolysis enthalpy of tobacco & $h_{\mathrm{Pyr}}$ & $\mathrm{MJ} / \mathrm{kg}$ & \multicolumn{4}{|l|}{0.0} \\
\hline Combustion enthalpy of char & $h_{\mathrm{Comb}}$ & $\mathrm{MJ} / \mathrm{kg}$ & \multicolumn{4}{|l|}{7.02} \\
\hline Fraction of combustion energy stored in the particle & $\Psi$ & 1 & \multicolumn{4}{|l|}{0.3} \\
\hline
\end{tabular}

Table 2. Data on flow resistance (for air under standard conditions) of the cigarette's components

\begin{tabular}{|c|c|c|c|}
\hline \multicolumn{4}{|c|}{ Flow resistance tensor $\mu \mathbf{D}$ in $\left[\mathrm{Pa} \cdot \mathrm{s} / \mathrm{m}^{2}\right]$} \\
\hline $4.0 \times 10^{9}$ & Unburnt cigarette paper $(=50 \mathrm{~cm} / \mathrm{min} \cdot \mathrm{kPa})$ & $2.0 \times 10^{4}$ & Burnt cigarette paper \\
\hline $2.8 \times 10^{4}$ & Unburnt tobacco rod $\left(=60 \mathrm{mmH}_{2} \mathrm{O}\right)$ & $2.0 \times 10^{4}$ & Burnt tobacco rod \\
\hline$\infty$ & Tipping paper & $\begin{array}{l}8.6 \times 10^{4} \\
8.0 \times 10^{6}\end{array}$ & $\begin{array}{l}\text { Filter }\left(=70 \mathrm{mmH}_{2} \mathrm{O}\right) \text {, axial direction } \\
\text { Filter, radial direction }\end{array}$ \\
\hline
\end{tabular}

continuity equation, the Navier-Stokes equation, an energy equation and transport equations for the gas species. These conservation equations are augmented by Darcy's law as a porous medium model and the ideal gas law. The variables in the continuum-mechanical model are pressure, density, gas temperature, flow velocity and the mass fractions of nitrogen $\left(\mathrm{N}_{2}\right)$, oxygen $\left(\mathrm{O}_{2}\right)$, water vapour $\left(\mathrm{H}_{2} \mathrm{O}\right)$ and combustion gases (CG).

With respect to the chemical reactions, however, the tobacco rod is modelled as a regular arrangement of spherical particles. These particles have properties similar to those of a tobacco shred with respect to density, heat capacity and chemistry. They will be consumed according to the chemical reaction rates and therefore act as point sources or sinks of energy and mass. To model these point sources and sinks the Dirac-function $\delta(x)$ will be introduced. Its defining properties (22) are

$$
\begin{aligned}
& \delta(x)=0 \text { if } x \neq 0 \text { and } \\
& \int_{V} \delta(x) \mathrm{d} V=1,
\end{aligned}
$$

if the domain of integration $V$ contains $x=0$. This function can be defined in rather general spaces, but for our needs $\boldsymbol{x}$ will denote a point in $R^{3}$ and $V$ will represent the common notion of volume. Consequently, the Dirac-function has the physical dimension of $1 / \mathrm{m}^{3}$.

The main interactions with the continuous model are the consumption of energy due to the heating of the particles by the gas flow, the consumption of oxygen during the chemical reactions and the emission of combustion gases, water vapour and energy during the combustion phase.

For each particle, mass, temperature and mass fractions of water, tobacco, char and ash are calculated.

The main advantages of this combination of a continuous and a discrete model are that an arrangement of discrete particles is a much more realistic representation of a tobacco rod than a continuous model and that the numerical treatment of this combination is rather robust. This simplifies and accelerates the calculations.

The meaning of all variable names and their values can be found in Tables 1-5.

\section{Continuous model - flow}

In the following $\phi(x, t)$ will denote the porosity, that is, the ratio of pore volume to total volume, at position $\boldsymbol{x}$ and time $t$, while $v$ will denote the superficial velocity, the gas density is denoted by $\rho$. The basis for the description of the flow are the continuity equation [1], derived in the Appendix,

$$
\frac{\partial \phi \rho}{\partial t}+\nabla \cdot(\rho v)=\sum_{i=1}^{N} \delta\left(x-x_{\mathrm{p}}^{i}\right) S_{\mathrm{m}}^{i}
$$

where the left-hand side includes the mass change and the convective mass transport, while the right-hand side describes the mass sinks/sources at the position of the tobacco particles. The sum is over all $N$ particles and $\boldsymbol{x}_{\mathrm{p}}^{i}$ 
Table 3. Data on diffusion constants of the cigarette's components

\begin{tabular}{lccc}
\hline Diffusion constants $D$ in $\left[\mathrm{m}^{2} / \mathrm{s}\right]$ at $273 \mathrm{~K}$ & Oxygen & Water vapour & Combustion gas $\left(\right.$ value for $\left.\mathrm{CO}_{2}\right)$ \\
\hline Unrestricted gas phase & $0.178 \times 10^{-4}$ & $0.239 \times 10^{-4}$ & $0.139 \times 10^{-4}$ \\
Unburnt cigarette paper & $1.000 \times 10^{-7}$ & $1.342 \times 10^{-7}$ & $0.781 \times 10^{-7}$ \\
Burnt cigarette paper & $1.200 \times 10^{-7}$ & $1.610 \times 10^{-7}$ & $0.937 \times 10^{-7}$ \\
Tipping and filter & 0.0 & 0.0 & 0.0 \\
\hline
\end{tabular}

Table 4. Data on the cigarette geometry and on parameters for the chemical reactions

\begin{tabular}{l|r|r}
\hline Geometrical data in $[\mathrm{m}]$ & Molar mass; $M_{i}[\mathrm{~g} / \mathrm{mol}]$ & Stoichiometric coefficients, $k_{i, j}[\mathrm{~kg} / \mathrm{kg}]$ \\
\hline $30 \times 10^{-6}$ Cigarette paper thickness & 32.0 Oxygen & $11.75 \mathrm{O}_{2}$, Combustion \\
$7.9 \times 10^{-3}$ Cigarette diameter & 28.0 Nitrogen & $33.00 \mathrm{H}_{2} \mathrm{O}$, Pyrolysis \\
$2.3 \times 10^{-2}$ Filter length & 18.0 Water & $2.50 \mathrm{H}_{2} \mathrm{O}$, Combustion \\
$35 \times 10^{-6}$ Tipping paper thickness & 58.0 Combustion gases & $8.00 \mathrm{CG}$, Pyrolysis \\
$2.7 \times 10^{-2}$ Tipping paper length & 1556.0 Tobacco & $10.00 \mathrm{CG}$, Combustion \\
$6.1 \times 10^{-2}$ Tobacco Rod length & 249.0 Char & 2.00 Char, Pyrolysis \\
\hline
\end{tabular}

Table 5. Parameters for the reaction rates of pyrolysis and combustion

\begin{tabular}{l|c|c|c}
\hline $\begin{array}{l}\text { Reaction } \\
\text { parameters }\end{array}$ & $\begin{array}{c}\text { Pre-exponential } \\
\text { factor } A\left[\mathrm{~s}^{-1}\right]\end{array}$ & $\begin{array}{c}\text { Activation energy } \\
E[\mathrm{~kJ} / \mathrm{mol}]\end{array}$ & $\begin{array}{c}\text { Exponent } \\
n[1]\end{array}$ \\
\hline Pyrolysis & $1.8 \times 10^{13}$ & 172.4 & 1 \\
Combustion & $1.7 \times 10^{10}$ & 146.5 & 1 \\
\hline
\end{tabular}

denotes the position of particle $i$, while $S_{\mathrm{m}}^{i}$ is the mass change $(\mathrm{kg} / \mathrm{s})$ in the gas caused by the chemical reactions occurring in particle $i$.

The source term $S_{\mathrm{m}}^{i}$ is calculated as the sum of all gas species consumed or produced during the chemical reactions.

$$
S_{\mathrm{m}}^{i}=S_{\mathrm{m}, \mathrm{N}_{2}}^{i}+S_{\mathrm{m}, \mathrm{O}_{2}}^{i}+S_{\mathrm{m}, \mathrm{H}_{2} \mathrm{O}}^{i}+S_{\mathrm{m}, \mathrm{CG}}^{i}
$$

Equations for the individual source terms in the above sum are given below.

The second equation is momentum conservation [3] as derived in the Appendix.

$$
\begin{aligned}
\frac{\partial}{\partial t}(\rho v) & +\nabla \cdot\left(\frac{\rho}{\phi} \boldsymbol{v} \otimes \boldsymbol{v}\right) \\
& =-\nabla(\phi p)+\nabla \cdot\left(\phi \mathbf{T}\left(\frac{v}{\phi}\right)\right)+\phi \rho \boldsymbol{g}+\mathbf{S}_{F},
\end{aligned}
$$

where $\mathbf{T}$ is the viscous stress tensor, defined in Eqn. [39]. The source term $\mathbf{S}_{F}$ in the momentum equation [3] contains additional forces due to the porous medium. It is usually modelled by Darcy's law (23) as

$$
S_{F, i}=-\mu D_{i j} v_{j}
$$

where a summation over $j=1 \ldots 3$ is implied. The flow resistance tensor $D_{i j}$ depends on the spatial position. Inside the cigarette its value is determined by the respective cigarette component and can be easily obtained by routine measurements of pressure drop or air permeability. The values can be found in Table 2 . With the exception of the filter, all cigarette components are assumed to be isotropic, so that the tensor can be represented as the product of a scalar and the Kronecker Delta, $D_{i j}=D \cdot \delta_{i j}$. Outside the cigarette the flow resistance tensor is zero.

\section{Continuous model - thermal energy equation}

The energy transport equation in porous media is solved in the following form (24)

$$
\begin{aligned}
\frac{\partial(\rho \phi h)}{\partial t} & +\nabla \cdot\left(\rho v\left(h+\frac{v^{2}}{2}\right)\right) \\
& =\nabla \cdot\left(\lambda_{g} \nabla T-\sum_{j} h_{j} \mathbf{J}_{j}\right)+f_{\text {rad }}(T) \sum_{i=1}^{N} \delta\left(\boldsymbol{x}-\boldsymbol{x}_{\mathrm{p}}^{i}\right) S_{h}^{i}
\end{aligned}
$$

where

$h=Y_{\mathrm{N}_{2}} h_{\mathrm{N}_{2}}(T)+Y_{\mathrm{O}_{2}} h_{\mathrm{O}_{2}}(T)+Y_{\mathrm{H}_{2} \mathrm{O}} h_{\mathrm{H}_{2} \mathrm{O}}(T)+Y_{\mathrm{CG}} h_{\mathrm{CG}}(T)$ Equations for the enthalpies of the gaseous components can be found in (20). The terms on the right hand side represent energy transfer due to conduction, species diffusion, $\mathbf{J}_{j}=$ $\rho \phi D_{j} \nabla Y_{j}$, and radiation. Radiation is modelled by a P1 radiation model, which is explained in more detail below. Viscous dissipation is neglected. Similarly to the continuity equation, the last term on the right hand side describes the enthalpy source/sink due to each tobacco particle. The source term $S_{h}^{i}$, physical dimension $\mathrm{J} / \mathrm{s}$, depends on the heat exchange with the tobacco particles. It is calculated by

$$
S_{h}^{i}=-\alpha A_{\mathrm{p}}^{i}\left(T\left(x_{\mathrm{p}}^{i}\right)-T_{\mathrm{p}}^{i}\right)+(1-\psi) h_{\mathrm{Comb}} \frac{\partial m_{\mathrm{Comb}}^{i}}{\partial t}
$$

which includes convective heat transfer from the particle to the gas flow and a certain fraction of the energy released during the combustion phase. The ideal gas law, taken from (24), will establish a relation between temperature and density by

$$
\rho=\frac{p_{0}}{R T}\left(\frac{Y_{\mathrm{N}_{2}}}{M_{\mathrm{N}_{2}}}+\frac{Y_{\mathrm{O}_{2}}}{M_{\mathrm{O}_{2}}}+\frac{Y_{\mathrm{H}_{2} \mathrm{O}}}{M_{\mathrm{H}_{2} \mathrm{O}}}+\frac{Y_{\mathrm{CG}}}{M_{\mathrm{CG}}}\right)^{-1} .
$$


The pressure $p_{0}$ is the ambient air pressure and will be assumed to be constant. Especially during smouldering but also during puffing, the relative pressure differences $\left(p-p_{0}\right) / p_{0}$ will usually not exceed 0.02 , while the relative temperature differences $\left(T-T_{0}\right) / T_{0}$ are usually much higher (up to 4 ). Therefore pressure effects on the density can be neglected compared to the temperature effects.

\section{Continuous model - radiation}

The exchange of heat by radiation is important due to the high temperatures occurring in a cigarette during smouldering and puffing. The transfer of heat by radiation from the particles to the gas flow and to other particles is modelled by a so called $\mathrm{P} 1$ radiation model, which is described in detail in (25) and (26). It is already implemented in the commercial CFD software package FLUENT as one of the standard radiation models. It offers some advantages with respect to computational effort compared to methods based on ray tracing.

The incident radiation $G$ is calculated by solving a diffusion-type equation

$$
\nabla \cdot(\Gamma \nabla G)+4 \pi\left(a \frac{\sigma T^{4}}{\pi}+E_{\mathrm{p}}\right)-\left(a+a_{\mathrm{p}}\right) G=0,
$$

where

$$
\Gamma=3\left(a+a_{\mathrm{p}}+\sigma_{\mathrm{p}}\right)^{-1}
$$

With respect to the particles, the equivalent scattering coefficient $\sigma_{\mathrm{p}}$, the equivalent absorption coefficient $a_{\mathrm{p}}$ and the equivalent emission $E_{\mathrm{p}}$ are calculated during particle tracking in FLUENT, by taking an average over all particles contained in a sufficiently small volume. Heat sources/ sinks due to particle radiation are included in the energy equation [5] by

$$
f_{\mathrm{rad}}(T)=-4 \pi\left(a \frac{\sigma T^{4}}{\pi}+E_{\mathrm{p}}\right)+\left(a+a_{\mathrm{p}}\right) G .
$$

\section{Continuous model - transport equations}

Each gas species is transported by convection and diffusion according to (24) by

$$
\frac{\partial \rho \phi Y_{j}}{\partial t}+\nabla \cdot\left(\rho v Y_{j}\right)=\nabla \cdot\left(\rho D_{j} \phi \nabla Y_{j}\right)+\sum_{i=1}^{N} \delta\left(\boldsymbol{x}-\boldsymbol{x}_{\mathrm{p}}^{i}\right) S_{\mathrm{m}, j}^{i}
$$

where the index $j$ is chosen from $\left\{\mathrm{N}_{2}, \mathrm{O}_{2}, \mathrm{H}_{2} \mathrm{O}, \mathrm{CG}\right\}$. The individual source terms $S_{\mathrm{m}, j}^{i}$, physical dimension $\mathrm{kg} / \mathrm{s}$, describe the mass of gas species $j$ produced by particle $i$ at the particle position $\boldsymbol{x}_{\mathrm{p}}^{i}$. They will be given in the next section. As all mass fractions $Y_{j}$ add up to 1 , the equations [11] are linearly dependent, so the transport equation for nitrogen will be omitted and its mass fraction calculated by

$$
Y_{\mathrm{N}_{2}}=1-Y_{\mathrm{O}_{2}}-Y_{\mathrm{H}_{2} \mathrm{O}}-Y_{\mathrm{CG}} \cdot
$$

\section{Discrete model - chemical reactions}

Each tobacco particle will be heated by the gas flow. To begin with, evaporation of water will reduce the particle's mass and heat capacity while consuming energy from the gas flow. At higher temperatures pyrolysis reactions will start and reduce the tobacco to char. Finally, the combustion reaction will convert char to ash. The chemical reactions can be summarized by

Evaporation: $\mathrm{H}_{2} \mathrm{O}_{(\mathrm{l})} \rightarrow \mathrm{H}_{2} \mathrm{O}_{(\mathrm{g})}$

Pyrolysis: $\quad$ Tobacco $\rightarrow k_{\text {Char, Pyr }}$ Char $+k_{\mathrm{H}_{2} \mathrm{O} \text {, Pyr }} \mathrm{H}_{2} \mathrm{O}_{(\mathrm{g})}$ $+k_{\mathrm{CG}, \mathrm{Pyr}}$ Combustion gases

Combustion: $\quad k_{\mathrm{O}_{2}, \mathrm{Comb}} \mathrm{O}_{2} \rightarrow k_{\mathrm{H}_{2} \mathrm{O}, \text { Comb }} \mathrm{H}_{2} \mathrm{O}_{(\mathrm{g})}+k_{\mathrm{CG}, \text { Comb }}$ Combustion gases + (Ash)

Ash is not treated explicitly in the equations, it is assumed to be an inert fraction of the tobacco. Given the mass change rates $(\mathrm{kg} / \mathrm{s})$ of particle $i$ due to evaporation $\partial m_{\text {Evap }}^{i} / \partial t$, pyrolysis $\partial m_{\mathrm{Pyr}}^{i} / \partial t$ and combustion $\partial m_{\text {Comb }}^{i} / \partial t$ we can calculate the mass change rates of the solids in particle $i$, according to the chemical reactions, by

$$
\begin{gathered}
\frac{\partial m_{\mathrm{p}, \mathrm{H}_{2} \mathrm{O}}^{i}}{\partial t}=-\frac{\partial m_{\text {Evap }}^{i}}{\partial t} \\
\frac{\partial m_{\mathrm{p}, \mathrm{Tob}}^{i}}{\partial t}=-\frac{\partial m_{\mathrm{Pyr}}^{i}}{\partial t} \\
\frac{\partial m_{\mathrm{p}, \mathrm{Char}}^{i}}{\partial t}=k_{\mathrm{Char}, \mathrm{Pyr}} \frac{M_{\mathrm{Char}}}{M_{\mathrm{Tob}}} \frac{\partial m_{\mathrm{Pyr}}^{i}}{\partial t}-\frac{\partial m_{\mathrm{Comb}}^{i}}{\partial t}
\end{gathered}
$$

Initially, the particle will consist of $12 \%\left(m_{\mathrm{p}, \mathrm{H}_{2} \mathrm{O}, 0} / m_{\mathrm{p}, 0}\right)$ water, $73 \%\left(m_{\mathrm{p}, \text { Tob }, 0} / m_{\mathrm{p}, 0}\right)$ combustible tobacco and $15 \%\left(m_{\mathrm{p}, \text { Ash }, 0} / m_{\mathrm{p}, 0}\right)$ non-combustible tobacco, which will remain as ash.

Furthermore we are able to calculate the creation rates of the gas components at particle $i$, which give us the source terms needed in the transport equations [11].

$$
\begin{gathered}
S_{\mathrm{m}, \mathrm{N}_{2}}^{i}=0 \\
S_{\mathrm{m}, \mathrm{O}_{2}}^{i}=-k_{\mathrm{O}_{2}, \mathrm{Comb}} \frac{M_{\mathrm{O}_{2}}}{M_{\mathrm{Char}}} \frac{\partial m_{\mathrm{Comb}}^{i}}{\partial t} \\
S_{\mathrm{m}, \mathrm{H}_{2} \mathrm{O}}^{i}=\frac{\partial m_{\mathrm{Evap}}^{i}}{\partial t}+k_{\mathrm{H}_{2} \mathrm{O}, \mathrm{Pyr}} \frac{M_{\mathrm{H}_{2} \mathrm{O}}}{M_{\mathrm{Tob}}} \frac{\partial m_{\mathrm{Pyr}}^{i}}{\partial t} \\
+k_{\mathrm{H}_{2} \mathrm{O}, \mathrm{Comb}} \frac{M_{\mathrm{H}_{2} \mathrm{O}}}{M_{\mathrm{Char}}} \frac{\partial m_{\mathrm{Comb}}^{i}}{\partial t} \\
S_{\mathrm{m}, \mathrm{CG}}^{i}=k_{\mathrm{CG}, \mathrm{Pyr}} \frac{M_{\mathrm{CG}}}{M_{\mathrm{Tob}}} \frac{\partial m_{\mathrm{Pyr}}^{i}}{\partial t}+k_{\mathrm{CG}, \mathrm{Comb}} \frac{M_{\mathrm{CG}}}{M_{\mathrm{Char}}} \frac{\partial m_{\mathrm{Comb}}^{i}}{\partial t}
\end{gathered}
$$

For those molar masses $M_{j}$ and stoichiometric coefficients $k_{j, l}$ of reactant $j$ in reaction $l, l \in\{$ Evap, Pyr, Comb $\}$, where only an equivalent value exists, such as tobacco, char and combustion gases, the values were chosen to reflect a typical cigarette and to ensure overall conservation of mass.

\section{Reaction rates}

For all particles $i=1 \ldots N$ the rate of evaporation is set constant according to 


$$
\frac{\partial m_{\text {Evap }}^{i}}{\partial t}=\left\{\begin{array}{ccc}
\mathrm{A}_{\mathrm{p}} J_{\text {Evap }} & \text { if } & T_{\mathrm{p}}^{i}>100^{\circ} \mathrm{C} \text { and } m_{\mathrm{p}, \mathrm{H}_{2} \mathrm{O}}^{i}>0 \\
0 & \text { otherwise }
\end{array}\right.
$$

Setting the evaporation rate to a constant was necessary to simplify the calculations and to keep the model complexity at a reasonable level. Of course, in reality the evaporation rate will depend in a complex manner on the temperature, on the particle composition and the surroundings of the particle. Nonetheless, this simplification allows the correct calculation of at least the total energy consumption during the evaporation phase.

The pyrolysis reaction rate is modelled by an Arrhenius rate equation similar to (5).

$$
\frac{\partial m_{\mathrm{Pyr}}^{i}}{\partial t}=-A_{\mathrm{Pyr}} \exp \left(-\frac{E_{\mathrm{Pyr}}}{R T_{\mathrm{p}}^{i}}\right)\left(\frac{m_{\mathrm{p}, \text { Tob }}^{i}}{m_{\mathrm{p}, \text { Tob }, 0}}\right)^{n_{\mathrm{Pyr}}} m_{\mathrm{p}, \text { Tob }, 0}
$$

The combustion reaction rate is likewise given as an Arrhenius rate equation, for example, as proposed in (4) or (7)

$$
\begin{aligned}
\frac{\partial m_{\text {Comb }}^{i}}{\partial t}= & -A_{\text {Comb }} \exp \left(-\frac{E_{\text {Comb }}}{R T_{\mathrm{p}}^{i}}\right)\left(\frac{Y_{\mathrm{O}_{2}} \rho}{\rho_{\mathrm{O}_{2}, 0}}\right)^{n_{\text {Comb }}} \\
& \left(\frac{m_{\mathrm{p}, \text { Char }}^{i}}{m_{\mathrm{p}, \text { Char }, 0}}\right) m_{\mathrm{p}, \text { Char }, 0},
\end{aligned}
$$

where

$$
m_{\mathrm{p}, \mathrm{Char}, 0}=k_{\mathrm{Char}, \mathrm{Pyr}} \frac{M_{\mathrm{Char}}}{M_{\mathrm{Tob}}} m_{\mathrm{p}, \mathrm{Tob}, 0}
$$

is the amount of char in a tobacco particle after complete pyrolysis. The mass fraction of oxygen $Y_{\mathrm{O}_{2}}$ and the density $\rho$ are evaluated at the position $\boldsymbol{x}_{\mathrm{p}}^{i}$ of particle $i$. The density $\rho_{\mathrm{O}_{2}, 0}$ is the density of oxygen in air under standard conditions. As the cigarette paper represents only a small fraction of the total cigarette mass, it is not treated explicitly in the chemical reactions. Instead, after the paper has reached $450{ }^{\circ} \mathrm{C}$ its permeability and its diffusion constant will change to that of burnt paper. This approach has also been applied in other studies, for example (7).

\section{Discrete model - thermal energy equation}

The energy balance of each tobacco particle $i$ is given by the following ordinary differential equation

$$
\begin{aligned}
m_{\mathrm{p}}^{i} c_{\mathrm{p}}^{i} \frac{\partial T_{\mathrm{p}}^{i}}{\partial t}= & \alpha A_{\mathrm{p}}^{i}\left(T\left(x_{\mathrm{p}}^{i}\right)-T_{\mathrm{p}}^{i}\right)+S_{\mathrm{p}, h}^{i} \\
& +\varepsilon_{\mathrm{p}} A_{\mathrm{p}} \sigma\left(\theta_{\mathrm{R}}^{4}-T_{\mathrm{p}}^{4}\right)+f_{\text {Cond }}^{i}\left(T_{\mathrm{p}}^{i}\right)
\end{aligned}
$$

where the heat source term is

$$
S_{\mathrm{p}, h}^{i}=-h_{\mathrm{Evap}} \frac{\partial m_{\mathrm{Evap}}^{i}}{\partial t}+h_{\mathrm{Pyr}} \frac{\partial m_{\mathrm{Pyr}}^{i}}{\partial t}+\psi h_{\mathrm{Comb}} \frac{\partial m_{\mathrm{Comb}}^{i}}{\partial t}
$$

and describes energy sinks due to evaporation and pyrolysis and the energy source due to the combustion reaction. The radiation temperature $\theta_{R}$ is given by

$$
\theta_{\mathrm{R}}=\left(\frac{G}{4 \sigma}\right)^{1 / 4}
$$

where the incident radiation $G$ is taken from the $\mathrm{P} 1$ radiation model, Eqn. [8].

The last two terms on the right hand side of Eqn. [24] account for the heat transfer due to radiation and due to conduction to other particles. Details with respect to the conduction model are given below.

It is assumed that the temperature in each particle is homogeneous and the conduction of heat inside the particle is therefore neglected. The heat transfer coefficient $\alpha$ from the spherical particles to the gas flow is evaluated using the correlation of RANZ and MARSHALL $(27,28)$

$$
N u=\frac{\alpha d_{\mathrm{p}}}{\lambda_{g}}=2+0.6 \operatorname{Re}^{1 / 2} \operatorname{Pr}^{1 / 3},
$$

where $N u, R e$ and $P r$ are the Nußelt, Reynolds and Prandtl numbers, respectively.

\section{Discrete model - heat conduction}

As the particles are not in direct contact, heat conduction from particle to particle cannot be described in a continuous model. Heat conduction, however, is an important means of heat exchange in the cigarette and therefore it is included in the particle model.

Let us assume that we have two neighbouring computational cells $j$ and $k$ which are connected by a surface of area $A_{j, k}$. In our model one particle is located on each cell surface of those cells lying inside the tobacco rod. Let $i$ be the particle on the surface between cells $j$ and $k$. We may approximate the heat transfer from cell $j$ to particle $i$ by

$$
\dot{Q}_{i, j}=\frac{\lambda_{s} A_{j, k}}{d_{j, i}}\left(T_{\mathrm{p}}^{i}-T_{j}\right)
$$

where $d_{j, i}$ is the distance from the centre of cell $j$ to the centre of particle $i$. Likewise the heat conduction from cell $k$ to particle $i$ can be written as

$$
\dot{Q}_{i, k}=\frac{\lambda_{s} A_{j, k}}{d_{k, i}}\left(T_{\mathrm{p}}^{i}-T_{k}\right),
$$

The remaining question is how an average temperature can be assigned to each cell for given particle temperatures. This is done by

$$
T_{j}=\frac{\sum_{i} m_{\mathrm{p}}^{i} c_{\mathrm{p}}^{i} T_{\mathrm{p}}^{i}}{\sum_{i} m_{\mathrm{p}}^{i} c_{\mathrm{p}}^{i}}
$$

where the summation is over all particles $i$ on the surfaces of cell $j$. The heat transfer by conduction to each particle is therefore given by

$$
f_{\text {Cond }}^{i}\left(T_{\mathrm{p}}^{i}\right)=\lambda_{s} A_{j, k}\left[\frac{T_{\mathrm{p}}^{i}-T_{j}}{d_{j, i}}+\frac{T_{\mathrm{p}}^{i}-T_{k}}{d_{k, i}}\right],
$$




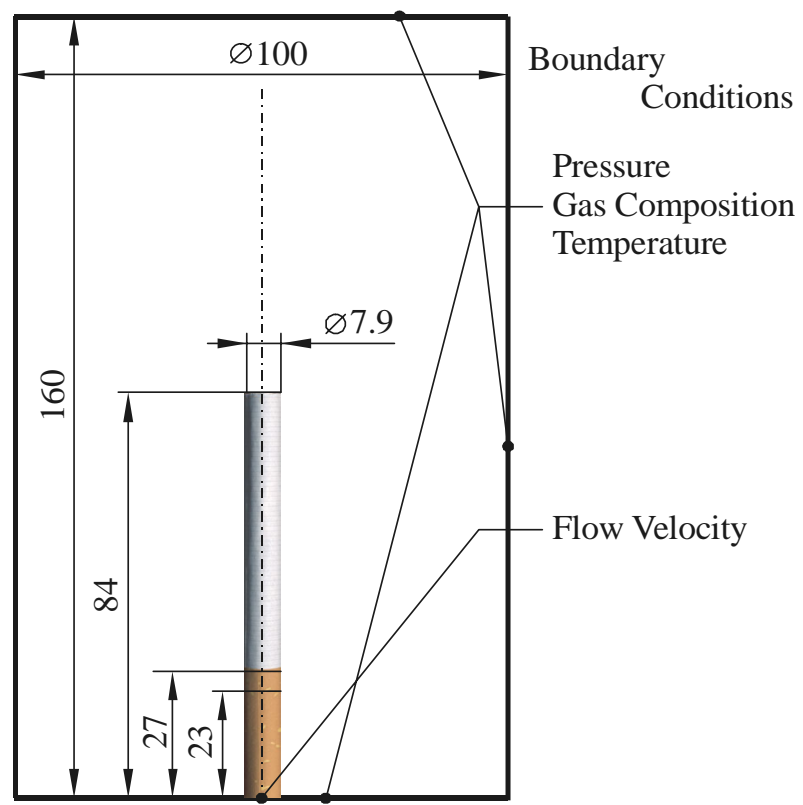

Figure 1. The computational domain and the boundary conditions for the simulation of a lit cigarette in a vertical position. All dimensions are in [mm].

\section{Estimation of material properties}

Apart from Darcy's law [4] and the ideal gas law [7], which were presented above, the dependence of the model parameters on the current state of the cigarette is included as follows. For each computational cell the porosity of the cigarette is calculated by

$$
\phi=1-0.15 \frac{\sum_{i} m_{\mathrm{p}}^{i}}{\sum_{i} m_{\mathrm{p}, 0}^{i}},
$$

where the summation is over all particles contained in the computational cell. As the particles are located on the cell surfaces, each particle is contained in two cells. Initially, porosity is 0.85 and it increases as the mass of the particles is reduced. The diffusion constants in the tobacco $\operatorname{rod} D_{j}$ are calculated from the values $D_{j, 0}$ for an unrestricted gas phase (see Table 3). Their dependence on porosity is taken from (7) and on temperature from (21).

$$
D_{j}=0.677 D_{j, 0} \phi^{1.18}\left(\frac{T}{273}\right)^{1.75}
$$

where temperature $T$ is in Kelvin. According to (21) the diffusion constant also depends on pressure, but this effect is neglected as the pressure difference is rather small compared to temperature differences.

According to (23), the effective heat conductivities of solid and gas phase, $\lambda_{s}$ and $\lambda_{g}$ respectively, depend on the porosity by $\lambda_{g}=\lambda_{g, 0} \phi$ and, $\lambda_{s}=\lambda_{s, 0}(1-\phi)$, where $\lambda_{g, 0}=$ $0.316 \mathrm{~W} /(\mathrm{mK})$ and $\lambda_{s, 0}=0.0242 \mathrm{~W} /(\mathrm{mK})$ [numerical values from (7)]. A dependence of the heat conductivities on the composition is neglected. The dependence of viscosity $\mu$ on temperature can be found in (21). It is assumed that its value does not depend on gas composition. The enthalpies $h_{j}$ of water vapour, oxygen and nitrogen and combustion gases (represented by carbon dioxide) and their dependence on temperature can be found in (20). The heat capacity of a tobacco particle will be calculated by weighting the heat capacity of the individual components according to their mass fractions. For water a value of $4.184 \mathrm{~kJ} /(\mathrm{kgK})$ is used, for tobacco, char and ash the heat capacity is set at 1.046 $\mathrm{kJ} /(\mathrm{kgK})$ [numerical value taken from (5)]. It is assumed that heat capacity does not depend on the temperature.

The permeability of the tobacco rod, the permeability of the cigarette paper and the diffusion constant of the cigarette paper are initially set at values for an unburnt state (see Tables 2 and 3) and switched to the value for a burnt state as soon as the particle temperature in the relevant computational cell exceeds $450{ }^{\circ} \mathrm{C}$.

\section{Initial and boundary conditions}

At the outer boundary of the computational domain the pressure, temperature and gas composition are fixed at ambient conditions. At the mouth end of the cigarette the flow velocity is prescribed depending on the smoking regime (smouldering, puffing, steady-draw). The geometry of the computational domain is shown in Figure 1.

As initial conditions pressure, temperature and gas composition are also set at ambient conditions within the entire computational domain and the tobacco is set at its unburnt state. To ignite the cigarette a heat source is introduced at the tip of the cigarette and air is drawn at the mouth end for two seconds. After this ignition period the pre-programmed smoking regime is applied.

For the simulation of a cigarette lying on a substrate, the substrate is modelled as a semi-infinite slab whose physical properties are the same as for the cigarette paper but the slab is assumed to be chemically inert.

\section{Numerical details}

For the numerical simulation the model was implemented in the software package FLUENT. The number of grid points was problem-dependent, with about 50,000 finite volumes for the two-dimensional simulations and 300,000 cells for the three-dimensional problems. The tobacco rod was simulated by approximately 20,000 discrete spherical particles for all simulations. The particle size was chosen such that the combined mass of all particles $(0.75 \mathrm{~g})$ and their total surface area was equal to typical values for a tobacco rod. The density of the tobacco particles was equal to the density of tobacco shreds and they were distributed in the tobacco rod in such a way that particle density was approximately homogeneous. Numerical values for the surface area and the number of tobacco shreds were taken from (14). The final number of particles was slightly problem dependent as it had to be adapted to the grid size. The discrete phase model in FLUENT assumes that the particles are moving with the flow, but in order to keep them at fixed positions their velocity was set to zero. Thus, from the discrete phase model only the heat exchange equations and the chemical reactions were considered. Special user-defined functions were needed to update the porosity according to Eqn. [32] and to implement the chemical reactions. 


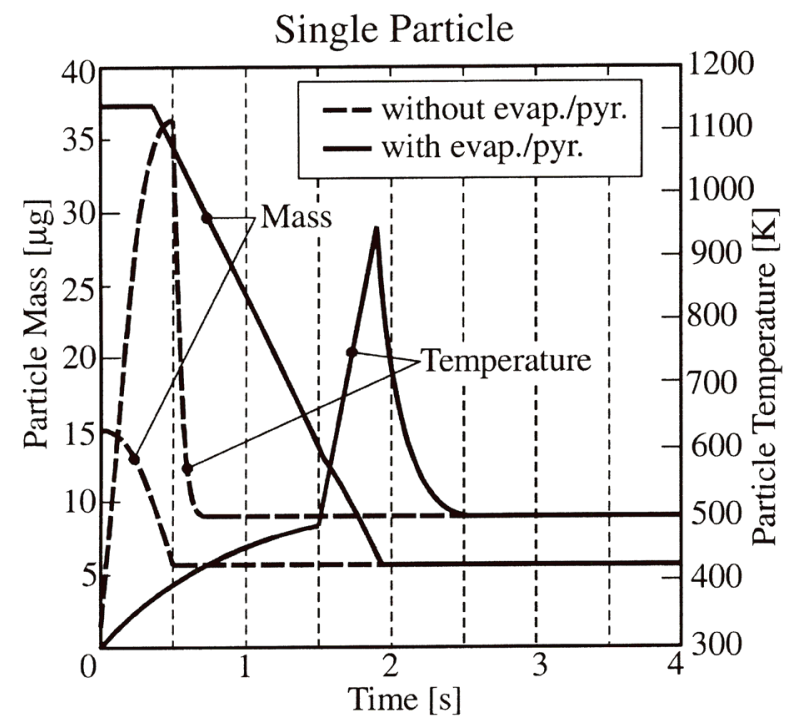

Figure 2. Simulated particle mass and temperature with and without evaporation and pyrolysis of a single spherical tobacco particle in an air flow of $0.05 \mathrm{~cm} / \mathrm{s}$ with a temperature of $500 \mathrm{~K}$

Temperature during Smouldering

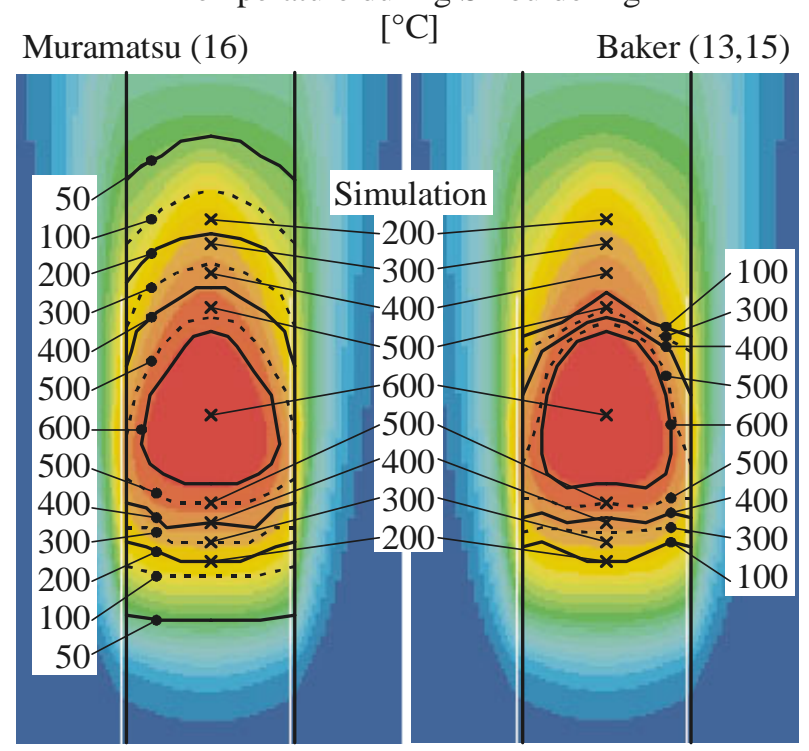

Figure 3. A comparison of the simulated temperature field (coloured) with the temperature contours measured by MURAMATSU (left, solid lines) and BAKER (right, solid lines). The temperature fields were calculated for vertical smouldering, the measurements are for horizontal smouldering.

As the system of differential equations is rather stiff, it was only possible to simulate time-steps in the order of $0.001 \mathrm{~s}$, and for this reason on a Dell Dual Processor workstation simulations times ranged from several hours for the twodimensional problems up to several days for the threedimensional problems.

\section{RESULTS}

To begin with, the isothermal flow model without any chemical reactions was simulated and the open draw resistance and the degree of filter ventilation were calculated for a wide variety of perforated tipping papers and cigarette papers. The correspondence with experimental data was good, the details can be found in (29).

Before the simulation of an entire cigarette, a single tobacco particle in an air flow with a constant temperature of $500 \mathrm{~K}$ and a velocity of $0.05 \mathrm{~m} / \mathrm{s}$ was simulated to verify that the chemical reaction model delivers reasonable results. The temperature and the mass of the particle over a time of $4 \mathrm{~s}$ are shown in Figure 2. In a first simulation the particle's composition was as given in Table 1 and evaporation and pyrolysis were included in the reaction model. In a second simulation, the particle consisted only of an inert solid fraction (ash) and char, representing the state after complete evaporation and pyrolysis. These two simulations were used to assess the effect of including pyrolysis and evaporation in the reaction model.

As a next step, a smouldering cigarette was simulated. A comparison of the simulation results with measured temperature fields inside the cigarette is shown in Figure 3. The solid lines represent temperature contours measured by BAKER (15) and MURAMATSU (16), while the coloured areas show the simulation result.

The second simulation was at a steady-draw of $2 \mathrm{~cm}^{3} / \mathrm{s}$. The cigarette was simulated for $150 \mathrm{~s}$ after ignition. By this time the temperature field and the gas concentration fields had ceased to change in shape except for a movement along the tobacco rod. The stationary temperature and oxygen profiles parallel to the cigarette axis at a distance of $0 \mathrm{~mm}$, $2 \mathrm{~mm}$ and $3 \mathrm{~mm}$ from the cigarette axis are shown in Figures 4 and 5 together with data measured by BAKER (12). All simulated profiles were shifted horizontally by the same distance to optically match BAKER's data.

Finally, a smoking regime was simulated similar to the International Standard (ISO) smoking regime with $35 \mathrm{~cm}^{3}$ puffs of $2 \mathrm{~s}$ duration, but at a rate of one puff every $30 \mathrm{~s}$ instead of $60 \mathrm{~s}$. The simulated position of the char line and the burn rates calculated from the data are shown in Figure 6. Temperature profiles parallel to the cigarette axis at a distance of $0 \mathrm{~mm}, 2 \mathrm{~mm}$ and $3 \mathrm{~mm}$ from the cigarette axis are shown in Figure 7 together with data measured by BAKER (13). A square-shaped puff was used in (13), while in our simulation sinusoidal puffs were taken. To be able to compare the simulation results with this set of data, the simulated temperature profiles were chosen at such a point in time that the volumetric flow during the puff matched the volumetric flow in BAKER's data.

Finally, for this puffing regime the velocity magnitude, the temperature and the combustion reaction rate for smouldering and puffing are shown in Figures 8 and 9, while the mass fractions of various gas species are shown in Figure 10 , again for smouldering and puffing. The pictures during puffing represent the situation one second after the start of the second puff.

As pointed out earlier, the model can also be used without modification for the simulation of cigarettes in a horizontal position. Due to the computational effort, however, only short periods of time could be simulated, such that during smouldering the stationary state is not yet fully developed, and for this reason the results are only displayed qualitatively. In the upper half of Figure 11, temperature and velocity fields of a cigarette smouldering freely in a 


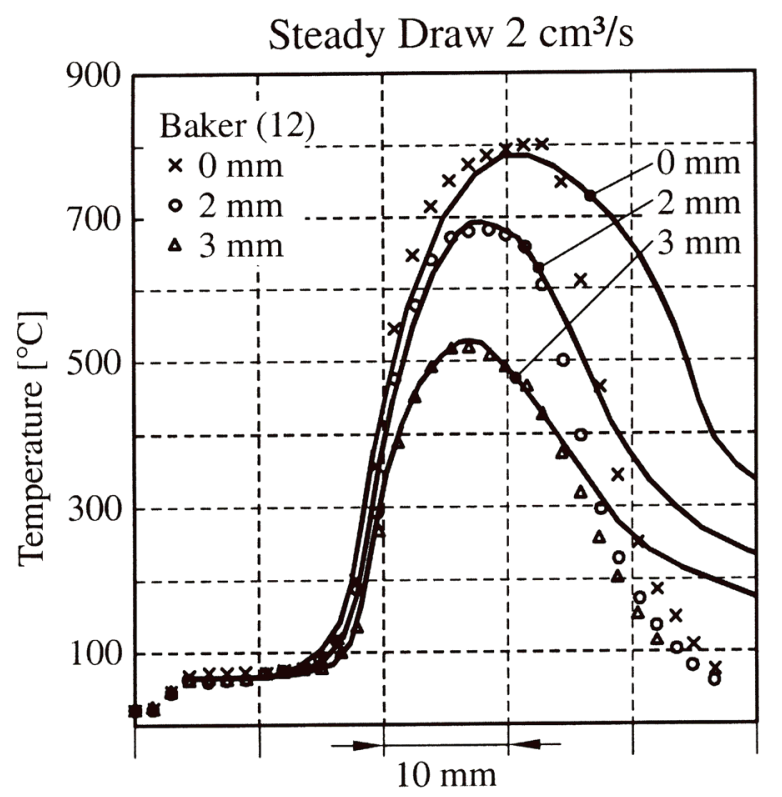

Figure 4. A comparison of the simulated stationary temperature profile during steady-draw (solid line) with data measured by BAKER (12, Figure 1). The profiles are taken parallel to the cigarette axis at a distance of 0,2 and $3 \mathrm{~mm}$ from the axis.

\section{Steady Draw $2 \mathrm{~cm}^{3} / \mathrm{s}$}

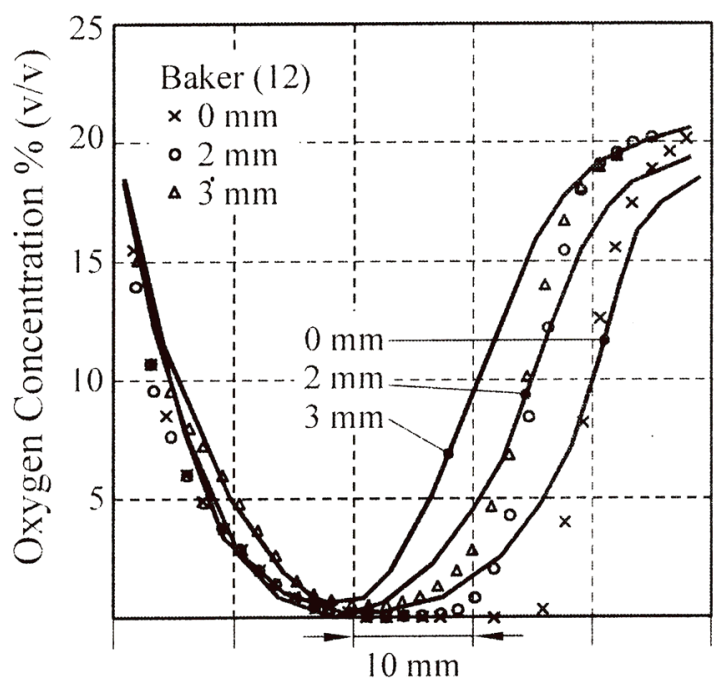

Figure 5. A comparison of stationary oxygen concentration profiles during steady-draw (solid line) with data measured by BAKER (12, Figure 2). The profiles are taken parallel to the cigarette axis at a distance of 0,2 and $3 \mathrm{~mm}$ from the axis.

horizontal position are shown. In the lower half the cigarette is lying on a substrate and the pictures represent the situation one second after the cigarette has been placed on the substrate.

\section{DISCUSSION}

\section{Single particle combustion}

From the results of the simulations of a single tobacco particle in a hot gas flow of constant temperature, composition and velocity, Figure 2, it can be seen that evaporation

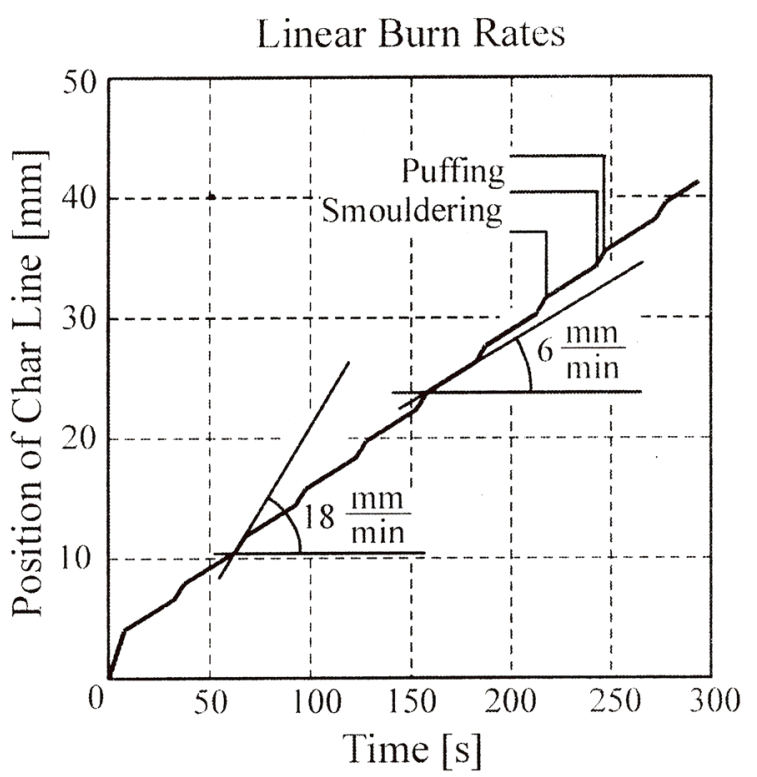

Figure 6. The position of the char line over time during a modified ISO smoking regime with $35 \mathrm{~cm}^{3}$ puffs of two second duration and one puff every $30 \mathrm{~s}$. The linear burn rate was calculated from the movement of the char line.

and pyrolysis are both processes which slow down the consumption of tobacco. The evaporation of water consumes energy from the gas flow. This slows down the heating of the tobacco particle, so that together with pyrolysis the start of the combustion reaction is delayed by about $1.5 \mathrm{~s}$. Furthermore the rise in temperature is smaller than for a particle consisting of char and ash only. The conclusion from this numerical experiment is that evaporation and pyrolysis play an essential role in controlling the burn rate of tobacco and they must be included in the reaction model.

\section{Comparison with measured data}

The comparison of the temperature fields, Figure 3, shows a rather good correspondence with MURAMATSU's data (16). The correspondence with BAKER's data (15) is also good for the $600{ }^{\circ} \mathrm{C}$ contour line, but not as good for the other contour lines. The main difference between the simulation and the experimental data is the orientation of the cigarette. The measurements in (15) and (16) were carried out on a cigarette in a horizontal position, while the model was simulated for a cigarette in a vertical position. In the simulation, buoyancy effects act along the cigarette axis and cause an elongation of the temperature contours. Nonetheless the qualitative correspondence with respect to shape and size of the temperature contours is good.

In Figure 4, the temperature profiles parallel to the cigarette axis during steady-draw correspond rather well with BAKER's data (12), but of course the effect of the vertical orientation of the simulated cigarette can again be seen, as the temperature remains high in the burnt part of the tobacco rod due to the gases moving upward along the cigarette axis. For the oxygen concentration profiles, Figure 5 , the correspondence with measured data is acceptable, especially if one considers the rather simple reaction models used in the simulation. The main effect that even 


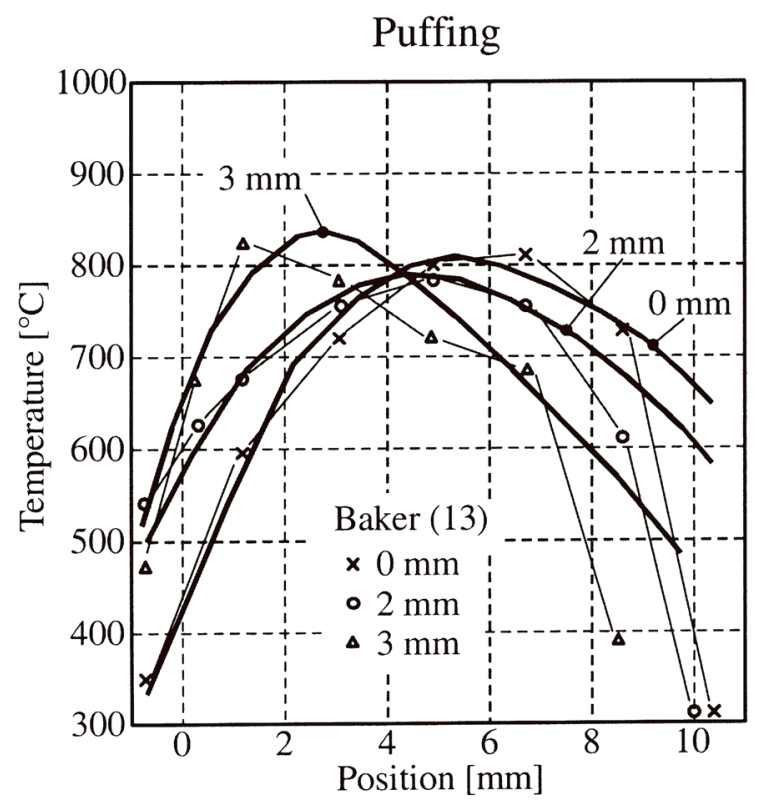

Figure 7. A comparison of simulated temperature profiles during ISO puffing (solid line) with data on a square-profile puff measured by BAKER (13, Figure 2). The simulated profiles are taken $0.44 \mathrm{~s}$ after the start of the second puff. All profiles are taken parallel to the cigarette axis at a distance of 0,2 and $3 \mathrm{~mm}$ from the axis. The origin of the $\mathrm{x}$-axis corresponds to the paper char line for the measured and the simulated profiles, the positive $\mathrm{x}$-direction points from the mouth end towards the lit end.

during steady-draw the combustion rate is controlled by the availability of oxygen, can be reproduced in the simulations.

The simulated burn rates observed during the modified ISO smoking regime of $6 \mathrm{~mm} / \mathrm{min}$ during smouldering and an average of $18 \mathrm{~mm} / \mathrm{min}$ during a puff correspond well with practical experience and data reported in other studies, for example (8).

Qualitatively, the temperature profiles during puffing, Figure 7, match those measured by BAKER (13) rather well, but again the simulated temperature in the burnt part of the tobacco rod is slightly higher, due to the vertical orientation of the cigarette.

Overall the correspondence with measured data is good for some global cigarette parameters, like degree of filter ventilation, open draw resistance and also burn rates. The temperature fields are also in good correspondence with measured data, while for some gas components the agreement is only acceptable. The reason for this is clearly the simple reaction model. The main focus of our model is, however, to correctly predict the thermo-physical behaviour of lit cigarettes rather than to describe detailed chemical reactions. The major advantage of the model proposed in this study is that in contrast to $(8,9)$ it does not use temperature fields or burn rates or any other data not a priori available as input.

This advantage, however, comes at a cost. A rather high number of model parameters need to be set, and some of these model parameters are either not known precisely or cannot be measured at all, such that estimates have to be used. This deteriorates the agreement with experimental data. In general, equations for heat and mass transfer as used in this model have in other applications shown surprisingly good correspondence with experimental data,

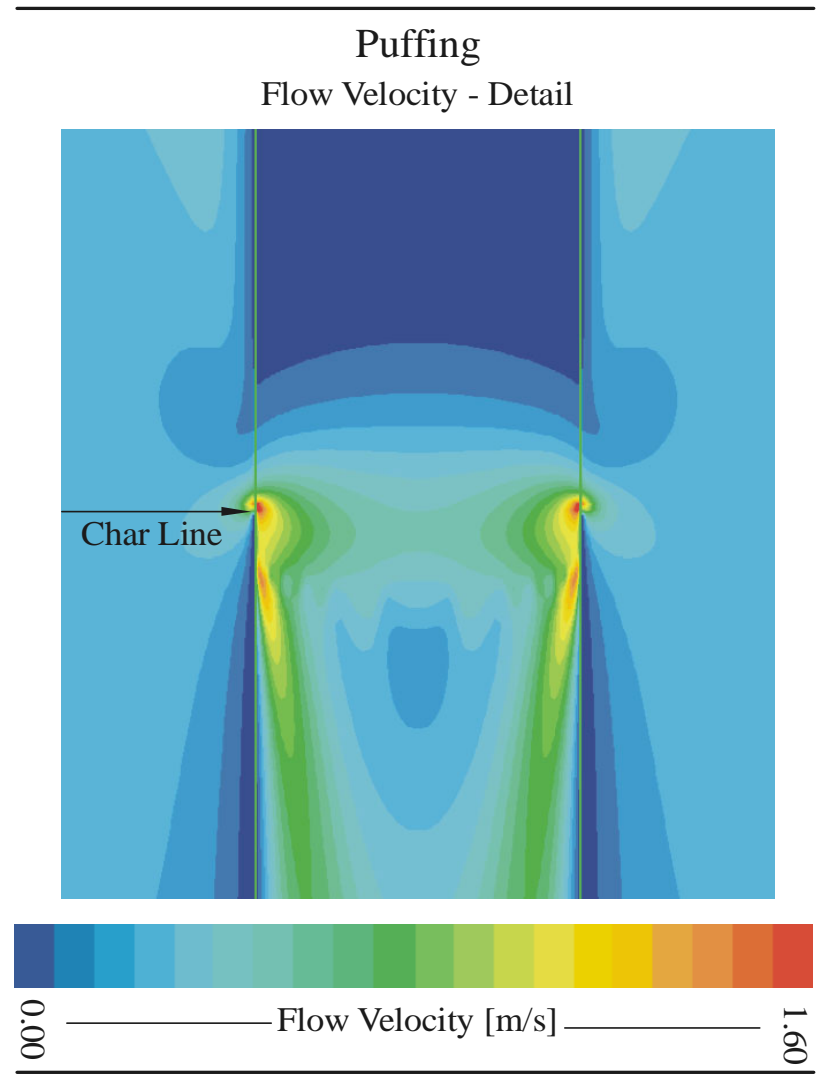

Figure 8. The flow velocity magnitude inside and outside the cigarette close to the glowing cone for ISO puffing. The picture represents the situation one second after the start of the second puff.

for examples see (10). Therefore we believe that an improvement in the precision of the model parameters rather than a refinement of the equations will have the most significant impact on the predictive quality of the model. An additional advantage of the proposed model is that a single model can be used to simulate smouldering, steadydraw and puffing. The same set of model parameters is used for all smoking regimes and the only difference is in the flow velocity prescribed at the mouth end. This could not be achieved with previously published models.

\section{Simulation of modified ISO smoking}

From the flow velocity magnitude fields during smouldering and during puffing, shown in Figure 9, we can see that a rather complex flow pattern develops at the outside of the cigarette. This flow pattern causes the transport of oxygen to the cigarette and the removal of combustion gases from the cigarette. It illustrates the importance of including the surroundings of the cigarette in the flow domain such that the flow at the outside of the cigarette can evolve naturally and is not predetermined by boundary conditions.

During puffing the effect of the air drawn at the mouth end can be clearly seen. The highest flow velocity occurs right at the position of the char line, where air enters into the cigarette (Figure 8 ). This has in the meantime often been confirmed by experiments (13). Below the char line the air moves downward, while above the glowing cone the air travels upward due to natural convection. In the area in 


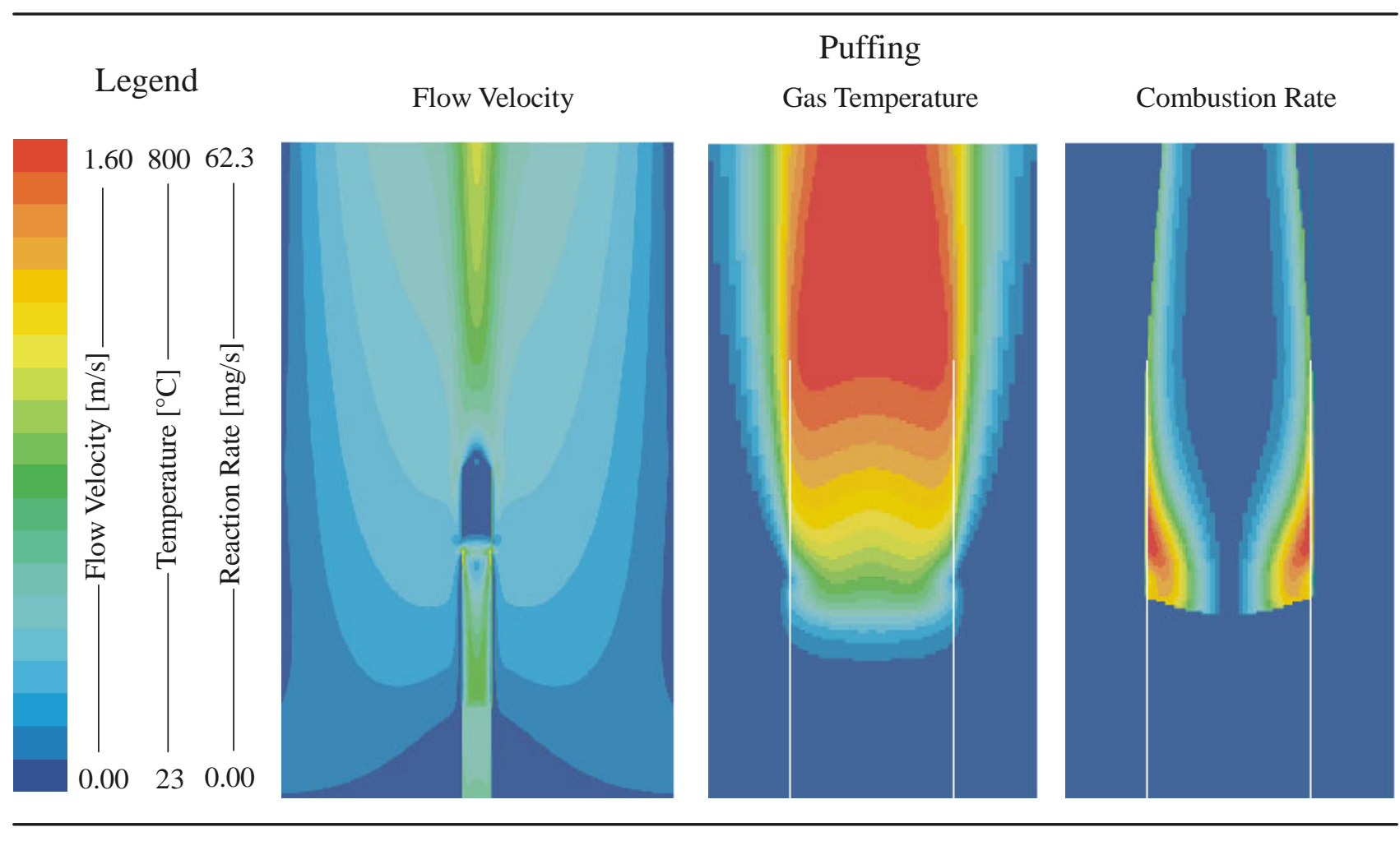

Legend

Flow Velocity

Smouldering

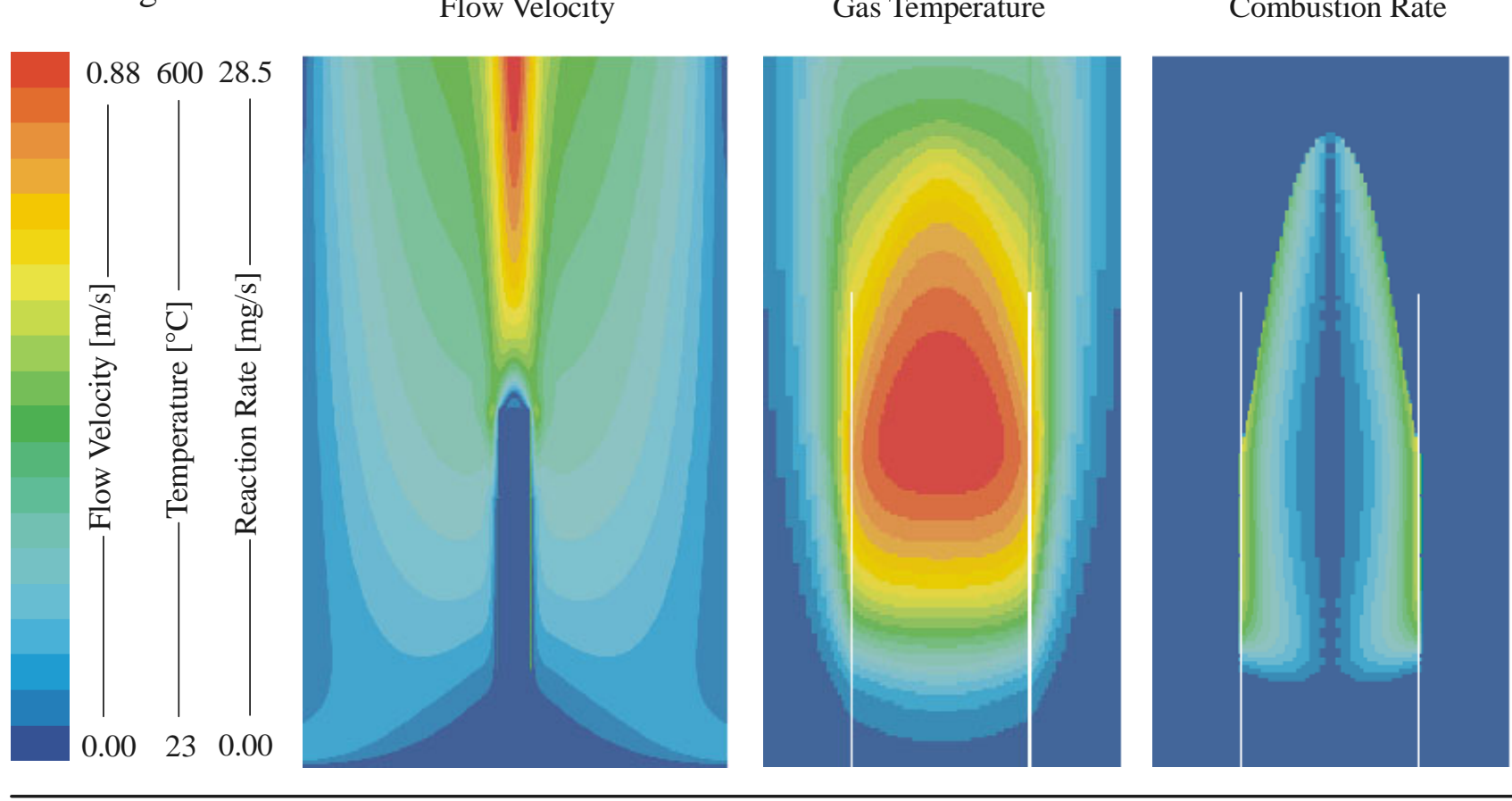

Figure 9. Flow velocity magnitude, gas temperature and combustion rate (char oxidation) inside and outside of a simulated cigarette in a vertical position during smouldering and during puffing. The pictures for puffing represent the situation one second after the puff start.

between, the flow velocities are very low and for the continuity of the velocity, there is at least one point where it is zero. Therefore combustion gases may accumulate in this region during puffing.

The combustion rate during puffing is much higher than during smouldering, with a clear maximum near the char line, where most of the oxygen is transported into the cigarette. In comparison, no such maximum occurs during smouldering. It has to be noted that the combustion rates in Figure 9 are mass change rates in $\mathrm{kg} / \mathrm{s}$. As the cigarette is modelled as a cylinder with homogeneous tobacco density, more mass is contained in the outer cylindrical shells than in the shells towards the centre. Consequently, it appears as if no reaction were occurring along the central cigarette axis, which is not the case. The change in density in $\mathrm{kg} /\left(\mathrm{s} \times \mathrm{m}^{3}\right)$ is still high along the central axis. 
Mass Fraction

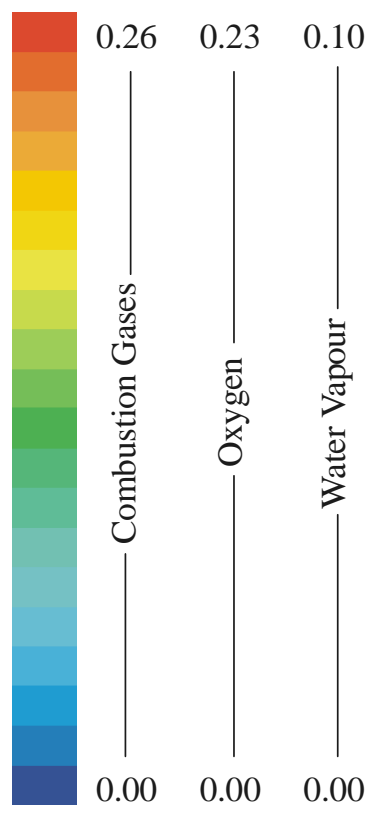

\section{Puffing - Gas Species}

Combustion Gases

Oxygen

Water Vapour

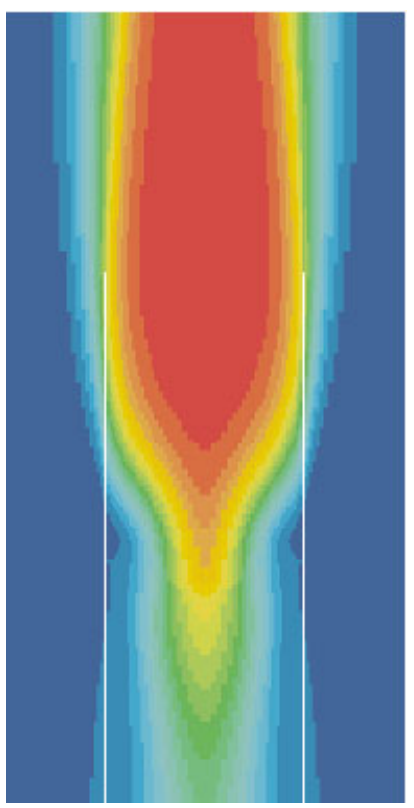

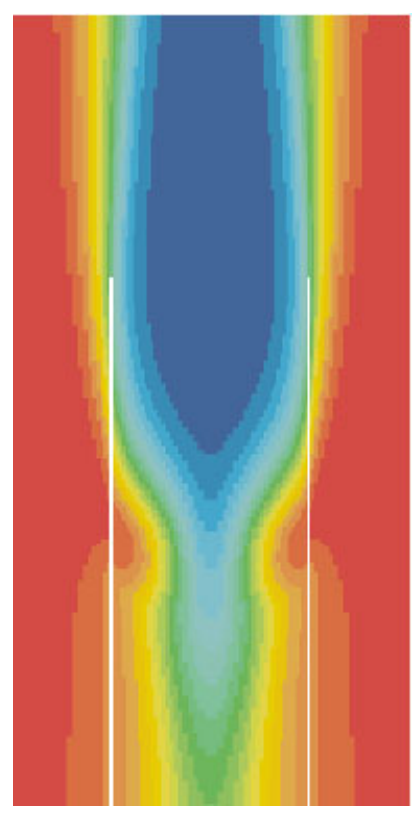

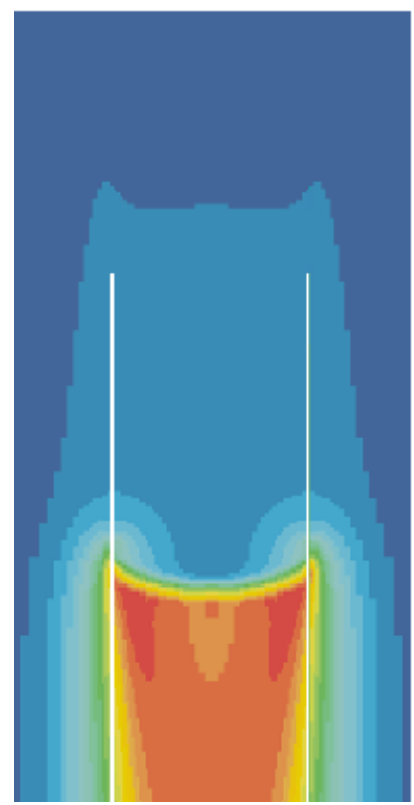

Mass Fraction

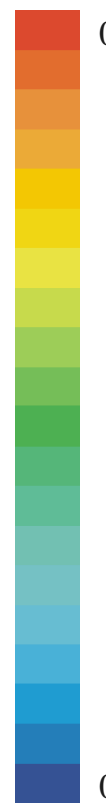

Combustion Gases

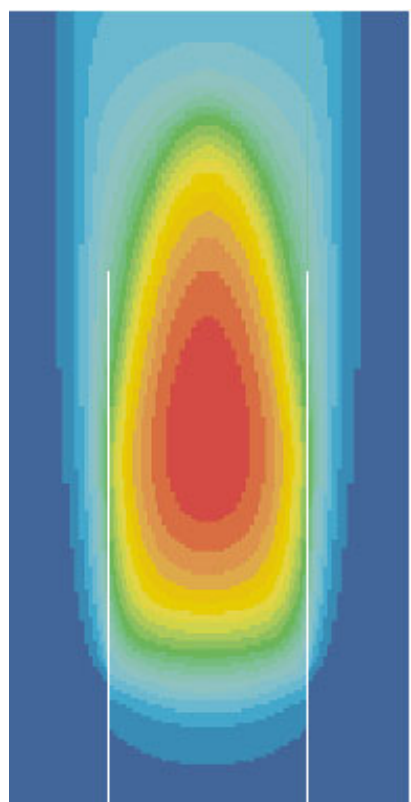

Smouldering - Gas Species

Oxygen

Water Vapour

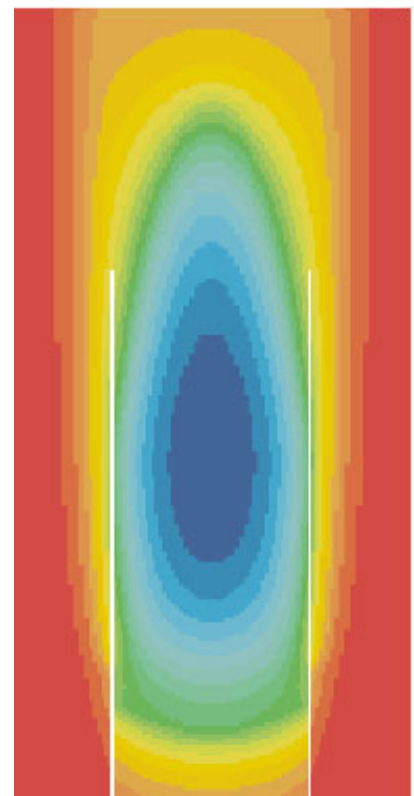

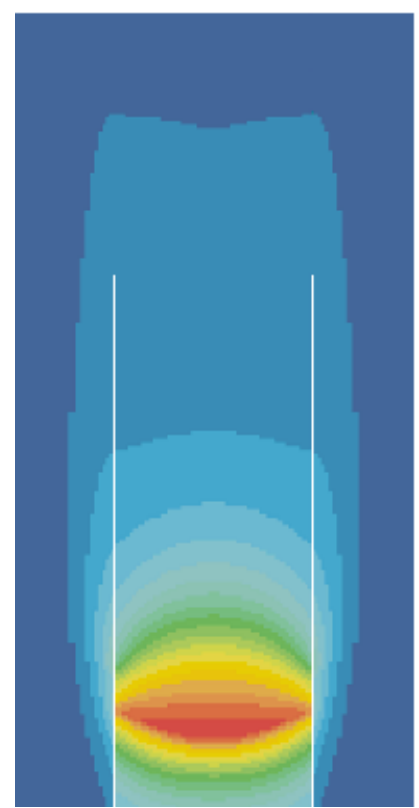

Figure 10. Calculated concentrations of combustion gases, oxygen and water vapour inside and outside a cigarette in a vertical position during smouldering and puffing. The pictures for puffing represent the situation one second after the puff start.

The gas species concentrations, Figure 10, can be easily explained in connection with the flow velocity magnitude from Figure 9. During smouldering the only transport mechanisms are natural convection and diffusion. Therefore all gases are transported upward and they will mix slowly. During puffing, air is drawn at the mouth end and most of the gases generated below the char line move downward, forming the mainstream smoke. Gases which are produced upstream of the char line will move upward. This effect is especially pronounced for water vapour. As most of the water vapour is generated at comparably low temperatures below the char line, practically all of it is drawn towards the mouth end. It has to be noted, of course, that the situation would be different if the cigarette were placed in a horizontal position. 


\section{Horizontal Smouldering}

Flow Velocity \& Combustion Gas Concentration

Flow Velocity and Temperature

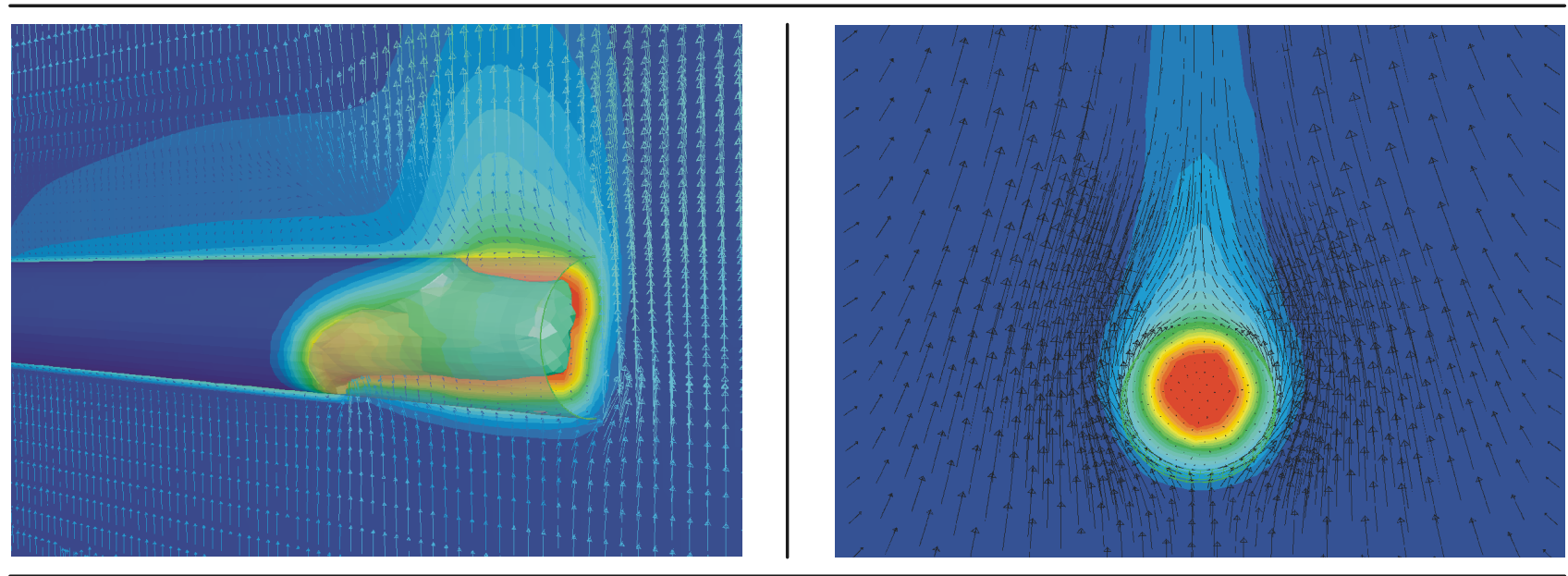

Horizontal Smouldering on a Substrate

Substrate Temperature

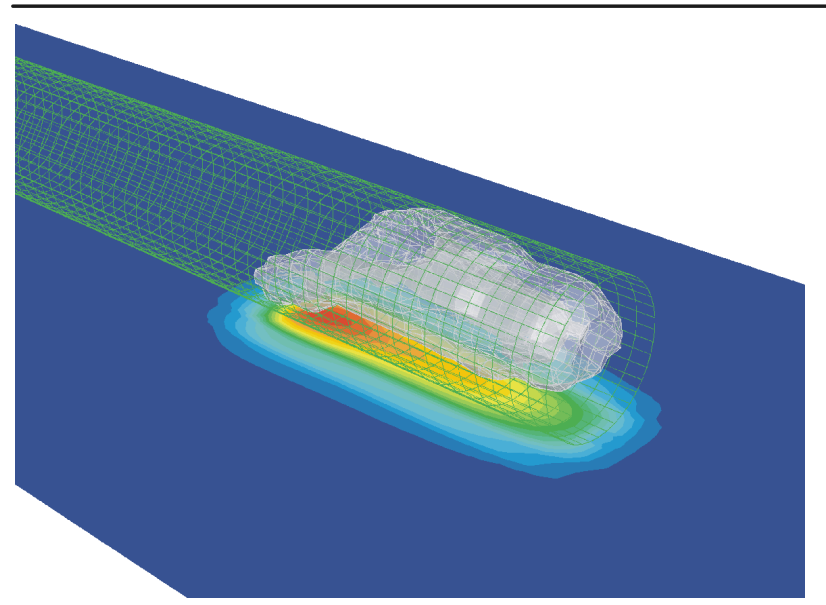

Flow Velocity and Temperature

Figure 11. Flow velocity, gas concentrations (top left) and temperature (top right) of a cigarette smouldering in a horizontal position. The substrate temperature (bottom left) and the flow velocity and temperature field (bottom right) for a cigarette smouldering in a horizontal position on a substrate. On the right are cross sections at the char line, viewed from the lit end towards the mouth end of the cigarette.

\section{Smouldering in a horizontal position}

By comparing the flow fields of a horizontal cigarette smouldering freely and a cigarette smouldering on a substrate, right-hand side of Figure 11, certain differences can be observed. While the convective flow around the cigarette is rather strong for free smouldering, the flow velocities are significantly lower for cigarettes on a substrate. This reduces the supply of oxygen to the glowing cone and consequently slows down the smouldering rate. The smouldering rate is also slowed down by the additional conduction of heat to the substrate, which can be seen in the front view of the cigarette. As the computational grid has not been optimised for a three-dimensional simulation, the computational effort was high and only short times could be simulated. Therefore, as can be easily observed in the lower left-hand picture of Figure 11, the glowing cone still has a shape similar to that of free smouldering. As can be confirmed by experiments, after some time the shape of the cone will be turned $180^{\circ}$ around its axis, because more oxygen is transported to the top of the cigarette than to the bottom. The possible application of this model to the simulation of the ignition strength test (30) is obvious.

While in this study CFD has proven to be a good tool for the simulation of cigarettes during smouldering and puffing, certain limitations still apply. First of all, the computational effort, especially for three-dimensional simulations is high. This effort can be reduced by optimising the computational grid and the size of the time-steps, but whenever chemical reactions are included the system of differential equations becomes rather stiff and only small time-steps can be taken. Secondly, good qualitative and semi-quanti- 
tative results can be expected for most simulations. But a high predictive quality cannot be expected as long as the value of many model parameters is known only vaguely. Trends caused by parameter changes, however, are usually reflected correctly in the simulations.

The proposed model can be extended easily, for example, by including chemical reactions of the cigarette paper. Due to the discrete model of the tobacco rod, the outermost layer of particles could be easily modified to represent cigarette paper instead of tobacco. This may make it possible to simulate the effect of changes in the paper composition.

\section{CONCLUSIONS}

The main conclusion is that a mathematical model can be established for the numerical simulation of freely chosen smoking regimes, such as smouldering, puffing or steadydraw. In contrast to previously published models, no modifications of the model or the model parameters are necessary. Only the boundary conditions need to be adapted according to the intended smoking regime. This can be achieved by combining a continuum-mechanical flow model with a discrete particle model for the chemical reactions occurring in the tobacco rod.

Furthermore the model only uses input data that can be measured before the cigarette has been lit. It does not need temperature fields or burn rates as input, instead these are output quantities of the simulation.

A comparison with experimental data for vertical smouldering, steady-draw and puffing has shown good correspondence for temperatures, burn rates and other thermophysical properties. Although the chemical reaction model is simple, reasonable correspondence with gas concentration profiles was achieved.

Qualitative results for horizontal smouldering and smouldering on a substrate were presented with a possible application to the ignition strength test.

Even though the correspondence with experimental data might in some respects not be perfect at the moment, the prospects are good that in the near future still better correspondence can be achieved when the important model parameters have been identified and are known more precisely. After all,

The purpose of models is not to fit the data but to sharpen the questions.

- Samuel Karlin: $11^{\text {th }}$ R.A.

Fisher Memorial Lecture, Royal Society 20, April 1983

\section{REFERENCES}

1. Egerton, A., K. Gugan, and F.J. Weinberg: The mechanism of smouldering in cigarettes; Combust. Flame 7 (1963) 63-78.

2. Gugan, K.: Natural smoulder in cigarettes; Combust. Flame 10 (1966) 161-164.

3. Ohlemiller, T.J.: Modeling of smoldering combustion propagation; Prog. Energy Combust. Sci. 11 (1985) $277-310$.
4. Summerfield, M., T.J. Ohlemiller, and H.W. Sandusky: A thermophysical mathematical model of steady-draw smoking and predictions of overall cigarette behavior; Combust. Flame 33 (1978) 263-279.

5. Muramatsu, M., S. Umemura, and T. Okada: A mathematical model of evaporation-pyrolysis processes inside a naturally smoldering cigarette; Combust. Flame 36 (1979) 245-262.

6. Chen, P.: A mathematical model of cigarette smoldering process; Beitr. Tabakforsch. Int. 20 (2002) 265-271.

7. Rostami, A., J. Murthy, and M. Hajaligol: Modeling of a smoldering cigarette; J. Anal. Appl. Pyrolysis 66 (2003) 281-301.

8. Saidi, M.S., M.R. Hajaligol, and F. Rasouli: An experimental and numerical analysis of puff hydrodynamics; Beitr. Tabakforsch. Int. 21 (2004) 157-166.

9. Saidi, M.S., M.R. Hajaligol, and F. Rasouli: Numerical simulation of a burning cigarette during puffing; J. Anal. Appl. Pyrolysis 72 (2004) 141-152.

10. Ferziger, J.H. and M. Perić: Computational methods for fluid dynamics; 2nd ed., Springer Verlag, Berlin, 1999.

11. Muramatsu, M.: An approach to modeling a burning cigarette; Beitr. Tabakforsch. Int. 21 (2005) 286-293.

12. Baker, R.R. and K.D. Kilburn: The distribution of gases within the combustion coal of a cigarette; Beitr. Tabakforsch. 7 (1973) 79-87.

13. Baker, R.R.: Temperature variation within a cigarette combustion coal during the smoking cycle; High Temp. Sci. 7 (1975) 236-247.

14. Baker, R.R.: Combustion and thermal decomposition regions inside a burning cigarette; Combust. Flame 30 (1977) 21-32.

15. Baker, R.R.: Variation of the gas formation regions within a cigarette combustion coal during the smoking cycle; Beitr. Tabakforsch. 11 (1981) 1-17.

16. Muramatsu, M., Y. Obi, T. Fukuzumi, and T. Keii: Influence of continuous puff velocity on combustion rate, temperature and temperature distribution in cigarettes; Nippon Nogei Kagaku Kaishi 46 (1972) 569-575.

17. Waymack, B.E., D.S. Kellogg, D.D. McRae, and R.W. Dwyer: Watts in a cigarette: Thermophysical properties of smoldering cigarettes; Tob. Sci. 41 (1997) 74-81.

18. Miura, K.: Oxygen diffusion though cigarette paper; Beitr. Tabakforsch. Int. 19 (2001) 205-208.

19. Baker, R.R.: The kinetics of tobacco pyrolysis; Thermochim. Acta 17 (1976) 29-63.

20. Beitz, W. and K.-H. Grote: Dubbel - Taschenbuch für den Maschinenbau, 20th Edition, Springer Verlag, Berlin, 2001.

21. Weast, R.C.: CRC Handbook of chemistry and physics, 64th edition, CRC Press, Florida, 1984.

22. Lang, S.: Real and functional analysis - Graduate texts in mathematics 142, $3^{\text {rd }}$ edition, Springer Verlag, 1993.

23. Bear, J.: Dynamics of fluids in porous media, Dover Publications, 1972.

24. Bošnjaković F.: Technische Thermodynamik Teil 1; $8^{\text {th }}$ Edition, Steinkopff Verlag, 1998.

25. Cheng, P.: Two-dimensional radiating gas flow by a moment method; AIAA Journal 2 (1964) 1662-1664.

26. Siegel, R., J.R. Howell: Thermal radiation heat transfer, Hemisphere Publishing Corporation, 1992.

27. Ranz, W.E. and W.R. Marshall: Evaporation from 
drops, Part I; Chem. Eng. Prog. 48 (1952) 141-146.

28. Ranz, W.E. and W.R. Marshall: Evaporation from drops, Part II; Chem. Eng. Prog. 48 (1952) 173-180.

29. Eitzinger, B., T. Haselgrübler, S. Pirker, and R. Kickinger: An application of CFD to thermodynamic aspects of smouldering cigarettes; Presentation at the $58^{\text {th }}$ Tobacco Science Research Conference 2004, Winston-Salem, NC, USA, Program Booklet and Abstracts No. 77, p. 70.

30. ASTM E 2187-02b: Standard method for measuring the ignition strength of cigarettes, ASTM Int. 2002.

APPENDIX. Derivation of Eqns. [1] and [3]

There are certain differences with respect to mass and momentum conservation of flows in porous media compared to free flows. The goal of this section is to derive Eqns. [1] and [3]. The porosity $\phi$ is defined as the ratio of the pore volume to the total volume, such that a volume $\Omega$ contains the void space $\phi \Omega$ and a surface $S$ has the open area $\phi S$ (23). We assume isotropic porosity. The physical velocity of the fluid in the porous medium is denoted by $\boldsymbol{u}$, but for many applications the superficial velocity $\boldsymbol{v}=\phi \boldsymbol{u}$ is defined to simplify the calculations. The volumetric flow can then be calculated by

$$
\int_{S} v \cdot n d S
$$

as if there were no porous medium. In the following we will derive mass and momentum conservation expressed in the physical velocity and then convert these equations to superficial velocity.

\section{Mass conservation}

The integral form of mass conservation without source terms for a free flow, taken from (10), is

$$
\frac{\partial}{\partial t} \int_{\Omega} \rho d \Omega+\int_{S} \rho \boldsymbol{u} \cdot \boldsymbol{n} d S=0
$$

In porous media an infinitesimal volume element is given by $\phi d \Omega$ and an infinitesimal surface element by $\phi d S$. Therefore in porous media Eqn. [34] reads

$$
\frac{\partial}{\partial t} \int_{\Omega} \rho \phi d \Omega+\int_{S} \rho \boldsymbol{u} \phi \cdot \boldsymbol{n} d S=0
$$

We apply Gauss' divergence theorem on the convective term to convert it into a volume integral and by noting that the choice of control volume $\Omega$ is arbitrary we obtain the differential form of mass conservation in porous media with physical velocity.

$$
\frac{\partial(\rho \phi)}{\partial t}+\nabla \cdot(\rho \phi u)=0
$$

Replacing the physical velocity by the superficial velocity we get

$$
\frac{\partial(\rho \phi)}{\partial t}+\nabla \cdot(\rho v)=0
$$

\section{Corresponding author:}

Bernhard Eitzinger

WFT Research

Fabrikstr. 20

4050 Traun

Austria

\section{Momentum conservation}

The integral form of momentum conservation for a free flow with surface and body forces, taken from (10), is

$$
\frac{\partial}{\partial t} \int_{\Omega} \rho \boldsymbol{u} d \Omega+\int_{S} \rho(\boldsymbol{u} \otimes \boldsymbol{u}) \cdot \boldsymbol{n} d S=\int_{S} \boldsymbol{\Sigma} \cdot \boldsymbol{n} d S+\int_{\Omega} \rho f d \Omega,
$$

where the stress tensor $\Sigma$ is, for Newtonian fluids, given by

$$
\boldsymbol{\Sigma}=-p \mathbf{I}+\underbrace{\mu\left(\nabla \boldsymbol{u}+(\nabla \boldsymbol{u})^{T}-\frac{2}{3}(\nabla \cdot \boldsymbol{u}) \mathbf{I}\right)}_{T(u)}
$$

and I denotes the second-order unity tensor. To account for the porosity we replace the infinitesimal volume $d \Omega$ and surface element $d S$ by $\phi d \Omega$ and $\phi d S$, respectively.

$$
\begin{aligned}
\frac{\partial}{\partial t} \int_{\Omega} \rho \boldsymbol{u} \phi d \Omega & +\int_{S} \rho(\boldsymbol{u} \otimes \boldsymbol{u}) \cdot \boldsymbol{n} \phi d S \\
& =\int_{S} \boldsymbol{\Sigma} \cdot \boldsymbol{n} \phi d S+\int_{\Omega} \rho \boldsymbol{f} \phi d \Omega
\end{aligned}
$$

We again apply Gauss' divergence theorem and argue as above with respect to the choice of control volume, which leads us to the differential form of the equation.

$$
\begin{aligned}
\frac{\partial(\rho \phi \boldsymbol{u})}{\partial t} & +\nabla \cdot(\rho \phi \boldsymbol{u} \otimes \boldsymbol{u}) \\
& =-\nabla(\phi p)+\nabla \cdot(\varphi \boldsymbol{T}(\boldsymbol{u}))+\rho \phi \boldsymbol{f}
\end{aligned}
$$

Finally, replacing the physical velocity $\boldsymbol{u}$ by the superficial velocity $\boldsymbol{v}=\boldsymbol{\phi} \boldsymbol{u}$ and assuming that gravity is the only body force we get

$$
\begin{aligned}
\frac{\partial(\rho v)}{\partial t} & +\nabla \cdot\left(\frac{\rho}{\phi} v \otimes v\right) \\
& =-\nabla(\phi p)+\nabla \cdot\left(\phi T\left(\frac{v}{\phi}\right)\right)+\rho \phi g
\end{aligned}
$$

